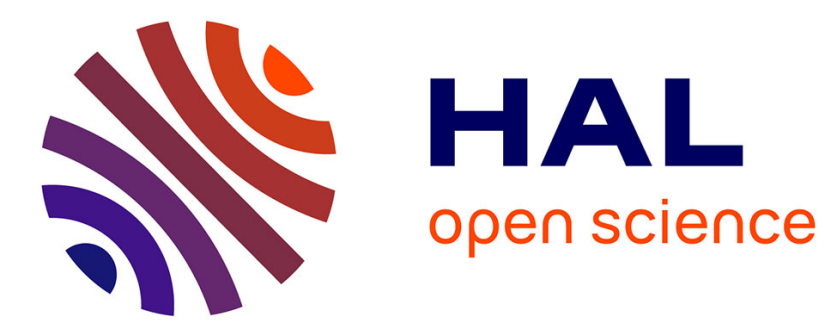

\title{
Inflation of Aira Caldera (Japan) detected over Kokubu urban area using SAR interferometry ERS data
}

\author{
D. Remy, S. Bonvalot, M. Murakami, P. Briole, S. Okuyama
}

\section{To cite this version:}

D. Remy, S. Bonvalot, M. Murakami, P. Briole, S. Okuyama. Inflation of Aira Caldera (Japan) detected over Kokubu urban area using SAR interferometry ERS data. eEarth Discussions, 2006, 1 (2), pp.151-165. hal-00330774

\section{HAL Id: hal-00330774 https://hal.science/hal-00330774}

Submitted on 8 Aug 2006

HAL is a multi-disciplinary open access archive for the deposit and dissemination of scientific research documents, whether they are published or not. The documents may come from teaching and research institutions in France or abroad, or from public or private research centers.
L'archive ouverte pluridisciplinaire HAL, est destinée au dépôt et à la diffusion de documents scientifiques de niveau recherche, publiés ou non, émanant des établissements d'enseignement et de recherche français ou étrangers, des laboratoires publics ou privés. 


\section{Inflation of Aira Caldera (Japan) detected over Kokubu urban area using SAR interferometry ERS data}

D. Remy ${ }^{1,{ }^{*}}$, S. Bonvalot ${ }^{1,2,{ }^{*}, \text { M. Murakami }}{ }^{3}$, P. Briole ${ }^{2}$, and S. Okuyama ${ }^{4}$

${ }^{1}$ Institut de Recherche pour le Développement (IRD), UR154, Toulouse, France ${ }^{2}$ Institut de Physique du Globe de Paris, 4 Place Jussieu, 75005 Paris, France

${ }^{3}$ Geographical Survey Institute, Mizusawa Geodetic Observatory, Mizusawa, Japan

${ }^{4}$ Kyoto University, Dept. of Geophysics, Kyoto, 606-8502, Japan

*now at: Dept. of Geophysics, University of Chile, Santiago, Chile

Received: 20 July 2006 - Accepted: 3 August 2006 - Published: 8 August 2006

Correspondence to: D. Remy (remy@dgf.uchile.cl)

Inflation of Aira Caldera (Japan) detected using

DinSAR

D. Remy et al.

\section{Title Page}

Abstract Introduction

Conclusions References

Tables Figures
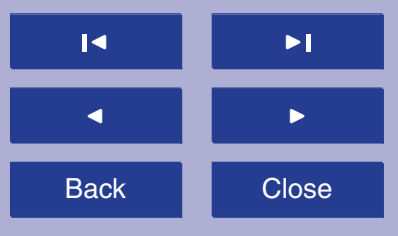

Back

Full Screen / Esc

Printer-friendly Version

Interactive Discussion 


\section{Abstract}

Nine ERS-1 and ERS-2 descending orbit data acquired over the Aira Caldera between June 1995 and November 1998 were used to create 31 differential interferograms. Although the interferograms exhibit a relatively low level of coherence, even for couples 5 sampling short time intervals (6 months), Differential Interferometric Synthetic Aperture Radar (DinSAR) reveals a pattern of range change signal during the observation period in the urban area of Kokubu city. The analysis of the ground deformation time series relative to the earliest ERS images evidenced a maximum uplift of $23 \mathrm{~mm}$ between the north and the south of the city during the studied period. Taking the reduced surface

of the coherent area into account, we performed a simple modelling of the deformation field assuming a spherical inflating source within an elastic half-space medium. This simple model predicts a source located beneath the centre of Aira Caldera with a maximum volume increase of $3010^{6} \mathrm{~m}^{3}$ between 1995 and 1997, which would produced an inflation of about $7 \mathrm{~cm}$ of the centre of Aira Caldera and $4 \mathrm{~cm}$ of the south of Kokubu 15 city. These results are in good agreement with other geophysical observations carried out on Aira caldera during this unrest period. Despite the limited spatial extent of the coherent areas around Aira Caldera, this study shows that DinSAR method using ERS data can be successfully used to detect subtle ground displacement changes of the volcanic complex and thus provides complementary information to ground-based geodetic monitoring of dynamic processes at Aira Caldera and Sakurajima volcano.

\section{Introduction}

Numerous papers have shown the potentialities of SAR (Synthetic Aperture Radar) interferometry data for ground deformation studies on volcanoes (Sigmundsson et al., 1999; Nishimura et al., 2001). Under optimal conditions a differential interferogram derived from two SAR images provides the possibility to monitor to within an accuracy of few $\mathrm{cm}$ topographic changes induced by internal volcanic processes over periods of
$1,151-165,2006$

Inflation of Aira

Caldera (Japan)

detected using

DinSAR

D. Remy et al.

\section{Title Page}

Abstract Introduction
Conclusions

Tables

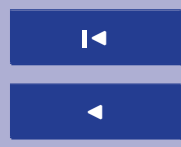

Back 
time up to several months or years. Furthermore, as satellite systems repeat their orbit on the order of weeks, it is now possible to generate deformation time series which help to better resolve time dependant deformation (Ferretti et al., 2001; Schmidt and Burgmann, 2003). In this paper we use the DinSAR method to examine ground defor5 mation occuring on the volcanic complex of Aira Caldera (Japan) within the 1995-1998 period (Fig. 1A). This Caldera and its post-caldera volcano, Sakurajima, are among the most active volcanic centers in Japan where significant ground deformations have been evidenced from ground monitoring networks since several decades (Omori, 1916; Yokoyama, 1971; Aramaki, 1984). The latest precise levelling survey conducted along 10 a coast road at Sakurijima clearly shows that the deflation of the ground around the Aira Caldera started in 1974 was turned into inflation in 1994 (Ishihara, 1999). In the same way, the analysis of a series of JERS interferograms (Murakami et al., 2001; Okuyama et al., 2001) acquired between 1994 and 1998 leads to the same conclusion. In this paper, we show here a clear evidence of ground deformation of the northern rim of the

15 Aira Caldera which is in good agreement with both independent studies. The analysis and interpretation of the interferometric time series are presented hereafter.

\section{DinSAR data acquisition and processing}

We analyzed a series of 31 interferograms produced from 9 ERS-1 and ERS-2 scenes acquired in descending orbits over Aira Caldera volcanic complex between June 1995 and November 1998 (Table 1). The differential interferograms were produced by the two pass method with DIAPASON software (CNES, 1996) using precise ERS orbits data (Sharroo et al., 1998). Figure 3A shows a typical example of a wrapped interferogram composed with ERS images spanning more than one year (orbits 20503 : 1995-06-17 and 10850: 1997-05-18). It can be noted that the interferogram exhibits 25 a relatively low level of coherence on the whole area and the image section between Sakurajima volcano and the coast is disconnected through water surface. However, the coherence on Kagoshima and Kokubu cities located respectively west and north

$1,151-165,2006$

Inflation of Aira

Caldera (Japan)

detected using

DinSAR

D. Remy et al.

Title Page

Abstract

Conclusions

Tables

References

Figures

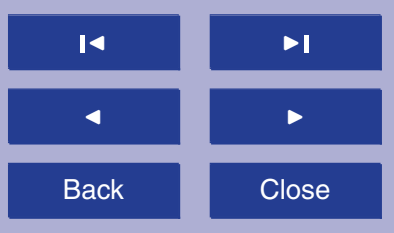

Full Screen / Esc

Printer-friendly Version

Interactive Discussion 
of the Bay of Kagoshima is maintained for over our SAR data observations. Examination of the differential SAR interferograms computed over time separations from one year to three years reveals a persistent interferometric phase signal located on Kokubu city whereas the phase on Kagoshima city remains generally flat. Such a phase sig5 nal (up to almost one fringe) can not be attributed to topographic residuals resulting from DEM inaccuracies used in the data reduction as it does not appear on various interferograms obtained from images spanning over less than one month with orbits perpendicular baselines greater than 350 meters. Effects of excess path delays produced by temporal changes of water vapour contents in the troposphere might be also 10 invoked to explain the interferometric signals on Sakurajima as they have been already evidenced on the studied area (Remy et al., 2003). The signal evidenced here on Kokubu city is unlikely to be produced by topography related tropospheric effects as the height variations along this coherent area are very weak (less than $200 \mathrm{~m}$ ) and do not reveal any correlation with the observed phase signal. If we can not rule out a possible contribution of residual transient tropospheric effects, it is noteworthy that all the independent interferograms (i.e. generated from images pairs acquired from different satellite tracks) having significant signals exhibit a phase variation with coherent patterns with both space and time (signal with relatively constant shape and with an amplitude increase with increasing time separation between SAR images). Taking these facts into account, we interpret the series of temporal signals observed over Kokubu city as mainly produced by a displacement towards the sensor line of sight associated to land uplift.

\section{Analysis of the DinSAR time series}

Most of the interferograms exhibits a low level of coherence which makes it difficult 25 to unwrapp the whole extension of images. Only two disconnected areas remain co-
$1,151-165,2006$

Inflation of Aira

Caldera (Japan)

detected using

DinSAR

D. Remy et al.

\section{Title Page}

Abstract Introduction

Conclusions

Tables

References

Figures

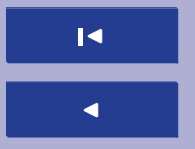

$>\mathbf{I}$

Back

Close herent during the observation period. Furthermore, the observation of the DinSAR series does not reveal a deformation pattern over Kagoshima city. This point will be 
addressed further in this paper. We thus focused our quantitative study, on a 10 by $10 \mathrm{~km}$ area that includes the whole coherent area over Kokubu city where the phase signal is clearly defined. Then, the filtered differential interferograms using a weighted power spectral density filter (Goldstein et al., 1988) were unwrapped using an imple5 mentation of a Network-flow Algorithm for Phase Unwrapping developed by Chen and Zebker (2002). In order to better understand and quantify the time dependent deformation, we generated a time series of interferograms relative to the earliest SAR image of our data set (orbit 20503 acquired the 17 June 1995) using a technique proposed by Usai (1999) and Lundgren and Usai (2001). Due to the limited spatial extent of the 10 selected coherent area it was not possible to define a reference point far away from the area of inflation which could be considered as a zero phase value for the phase unwrapping process. Consequently, in order to make comparable the phase variations both in space and time within the studied area and considering the decreasing pattern of the signal towards the north, we then fixed arbitrarily a reference site on 15 north Kokubu (noted $\mathrm{P}$ in Fig. 1B) for which the observed deformation is assumed to be minimal over the studied period. The reference phase value for this site has been calculated by averaging the unwrapped phase values for the surrounding pixels within a $200 \mathrm{~m}$ squared box. This minimal deformation phase value has thus been used as a common reference for the whole time series of unwrapped interferograms.

By this process, the resulting field deformation maps give a relative measure of the ground displacement with respect to this fixed reference point. In the first stage, in order to detect the presence of noise or unwrapped phase errors that could lead to severe misinterpretations, we estimated the phase unwrapping biases by comparing each subset of three interferograms composed of a linear combination of three SAR images. At a given pixel the phase value closure for all subsets of interferograms should be closed to zero. This analysis enhances the consistency of our dataset of unwrapped interferograms for which a $90 \%$ of the pixels have closure discrepancies lower than $4 \mathrm{~mm}$. Then, the network of 31 interferograms was used to give an optimal measure of the surface deformation at Kokubu city expressed in centimeter for each in-
$1,151-165,2006$

Inflation of Aira

Caldera (Japan)

detected using

DinSAR

D. Remy et al.

Title Page

Abstract Introduction

Conclusions

Tables

References

Tables

Figures

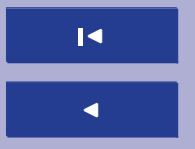

$>1$

-

Back

Close

Full Screen / Esc

Printer-friendly Version

Interactive Discussion 
terferogram relative to the reference image (orbit 20503). At a given pixel the observed deformation relative to the chosen reference point is adjusted to minimize the closure discrepancies within the network using a least square inversion. Figure 1.B shows the resulting adjusted deformation field for the eight images relative to the reference image 5 (see Table 1). As an example, a result is given for the interferogram orbits 2050310850 in Fig. 2B were the raw DinSAR time series along a north-south profile PP' (see Fig. 1B) is compared with the compensated one obtained from the adjustment of 8 images. This comparison evidences the good adequacy of the compensation process of the original DinSAR data. The resulting deformation map series clearly reveals a 10 pattern of uplift between June 1995 to May 1997 with as much as $23 \mathrm{~mm}$ of differential uplift between the south and the north of Kokubu area. The Fig. 2A plots the maximum relative deformation values observed along the P-P' profile at the respective SAR images acquisition dates. The good agreement of measured uplifts obtained for image orbits 23509 and $03836(8 \pm 1 \mathrm{~mm}, 6 \pm 1 \mathrm{~mm})$ and images orbits images orbits 20503 15 and $21004(0 \pm 1 \mathrm{~mm},-1 \pm 1 \mathrm{~mm})$ spanning respectively one and 35 days enhances the robustness of the approach followed to quantify the surface deformation occurred during the studied period over Kokubu area. The DinSAR time series (Figs. 1B and 2A) confirm that a differential uplift up to $23 \mathrm{~mm}$ between north and south of Kokubu area occurred within August 1995 and May 1997 (within days 211 to 701) followed by 20 a stop in the uplift observed between May 1997 and October 1998) and finally by a period of an apparent rapid subsidence of few $\mathrm{mm}$ amplitude between October and November 1998. We believe that this apparent decrease in the uplift is mainly due to signal contamination by local atmospheric heterogeneities. Considering the results of other ground deformations studies carried out from JERS and GPS data on this volcanic complex for the similar time period (Okuyama et al., 2001) this uplift-subsidence sequence evidenced here on Kokubu area between 1995 and 1998 might be considered as a part of a larger ground deformation signal resulting from inflation-deflation processes within the main magma chamber already identified below the Aira caldera.

Inflation of Aira

Caldera (Japan)

detected using

DinSAR

D. Remy et al.

Title Page

Abstract

Conclusions

Tables

References

Figures

14

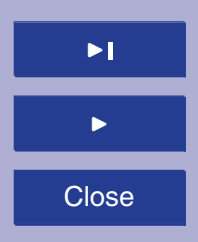

Back

Full Screen / Esc

Printer-friendly Version

Interactive Discussion 


\section{Source of crustal deformation}

We used a simple approach in order to investigate this hypothesis and to quantify the source for crustal deformations located in the center of Area caldera which may produce the observed signal at Kokubu city. Such an approach is facilitated by the 5 low topography in the study area that makes possible to use the elastic half space assumption. We thus solved the best fitting of our uplift measurements using a point source model as already proposed for this volcano in previous studies (Murakami et al., 2001; Okuyama et al., 2001). The limited spatial extent of the coherent area, which will only represent a small segment of the deformation field, makes it difficult to estimate so source and its associated variation. We decided to reduce the number of 4 parameters to three by assuming a deformation source located $10 \mathrm{~km}$ below the sea level in accordance with the above mentioned results of ground deformations studies for this unrest period. We solved the best fitting point source model using a non-linear least square inversion approach. Table 2 shows the resulting solutions and rms between the observed and predicted signals for three interferograms having the maximum observed signal. The resulting best fit models for these two years differential interferograms involve an equivalent volumetric change of a sphere located beneath Aira Caldera ranged between $2910^{6} \mathrm{~m}^{3}$ and $3010^{6} \mathrm{~m}^{3}$. Figure $3 A$ and $B$ show respectively the interferograms formed by the images orbits 20503-10850 and the range displacements as predicted by the model over the whole Aira caldera. The correspondence between the modeled and the observed data on Kokubu area is enhanced in Fig. $3 \mathrm{C}$ and $\mathrm{D}$ The modeled radar line of sight displacement generated by this model in the other coherent urban area (Kagoshima city), which was not used in the inversion process, would locally produce a variation in amplitude lower than $6 \mathrm{~mm}$.
This weak deformation signal associated with the maximum uplift observed on Kokubu city explain the lack of interferometric signal observed in this urban area.
1, 151-165, 2006

Inflation of Aira

Caldera (Japan)

detected using

DinSAR

D. Remy et al.

\section{Title Page}

Abstract Introduction

Conclusions

Tables

References

Figures

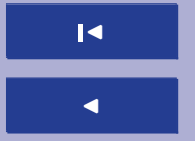

DI

Back

Close

Full Screen / Esc

Printer-friendly Version

Interactive Discussion 


\section{Conclusion}

Despite the limited spatial extent of the coherent areas around Aira Caldera, ERS data has been successfully used in this study for measuring a sequence of ground displacement changes occurred on this volcanic complex during a three years period. The in5 terferogram time series analysis performed on the SAR coherent area of Kokubu city evidences that at least $23 \pm 1 \mathrm{~mm}$ of relative upflit has occurred within June 1995 and May 1997 between the north and the south of this urban area. The source modelling of the crustal deformations using the Mogi's model predicts a source located beneath the centre of Aira Caldera which is compatible with an expansion of a magma body. The best fitting model that explains the maximum uplift corresponds to a volume increase of $3010^{6} \mathrm{~m}^{3}$ which would produce a predicted uplift of about $70 \mathrm{~mm}$ of the caldera floor above the inflation source. These results are in good agreement with those obtained by recent observations based on JERS,GPS and precise levelling data spanning a similar time period which predicts a maximum volume increase of $2810^{6}$ between 15 July 1994 and Mars 1997 (Murakami et al., 2001; Okuyama et al., 2001) and suggest that both results are highly reliable. Although the ERS interferograms exibit a lowest level of coherence than JERS interferograms, the accuracy of the orbital state vectors provided by Delft Institute and the highest sensibility of the C-band to ground deformations enables to detect subtle crustal deformation signal, such as those evidenced here. Obviously, the limited spatial extent of the coherent area does not make possible to take the whole caldera structure into account, but these results give first order information on the source location and volume variation occurred during the 1995-1998 period. This study also confirms that the analysis of space derived deformation field maps over the Kokubu city may provide useful additional information to other geodetic 25 measurements to better understand the dynamical processes at Aira caldera. Finally, this study shows that Kokubu city may be considered as an excellent area to apply methods such those based on InSAR persistent scatterer (Ferretti et al., 2001; Hooper et al., 2004) for analysing crustal deformation in relation with the Sakurajima activity.
$1,151-165,2006$

Inflation of Aira

Caldera (Japan)

detected using

DinSAR

D. Remy et al.

Title Page

Abstract Introduction

Conclusions

Tables

References

Figures

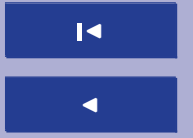

DI

Back

$\rightarrow$

Close

Full Screen / Esc

Printer-friendly Version

Interactive Discussion 
Acknowledgements. We thank N. Pourthié and $\mathrm{H}$. Vadon for technical help in the SAR data processing with DIAPASON software. The ERS images processed in this study were obtained through ESA research project. This study was supported by IRD (Dept. DME), IPGP (contribution No. $x x x x$ ) and GDR INSAR.

\section{References}

Aramaki, S.: Formation of the Aira Caldera, Southern Kyushu, 22,000 Years ago, J. Geophys. Res., 89(B10), 8485-8501, 1984.

Chen, C. W. and Zebker, H. A.: Phase unwrapping for large SAR interferograms: Statistical segmentation and generalized network models, IEEE Transactions on Geoscience and Remote Sensing, 40, 1709-1719, 2002.

CNES: Philosophie et mode d'emploi de la chaîne logicielle interférométrique DIAPASON, Toulouse, France, 1996.

Ferretti, A., Prati, C., and Rocca, F.: Permanent Scattered in SAR interferometry, IEEE Trans. Geosci. Remote Sens, 39(1), 8-20, 2001.

15 Goldstein, R. M., Zebker, H. A., and Werner, C. L.: Sattelite radar interferometry: two dimensional phase unwrapping, Radio Sci., 23, 713-720, 1988.

Hooper, A., Zebker, H. A., Segall, P., and Kampes, B.: A new method for measuring deformation on volcanoes and other natural terrains using INSAR persitent scatterers, Geophys. Res. Lett., 31, L23611, doi:10.1029/2004GL021737, 2004.

Ishihara, K.: Sakurajima activity for the period from 1995 to 1998, IUGG 22nd General Assembly, Birmingham, UK, 1999.

Lundgren, P. and Usai, S.: Modeling surface deformation observed with synthetic aperture radar interferometry at Campi Flegrei caldera, J. Geophys. Res., 106, 19 355-19 366, 2001.

Murakami, M., Okuyama, S., Briole, P., Remy, D., Tobita, M., Fujirama, S., and Yarai, H.: Comparison of JERS-1 L-band InSAR and ERS C-band Insar around Sakurajima, edited by: Institute, E. R., ERI Workshop on "Significance of L-band Interferometric SAR", Tokyo, Japan, 2001.

Nishimura, N., Ozawa, S., Murakami, M., Sagiya, T., Tada, T., Kaidzu, M., and Ukawa, M.: Crustal Deformation caused by magma migration in the nothern Izu Island, Japan, Geophys. Res. Lett., 28, 3745-3748, 2001.

Inflation of Aira

Caldera (Japan)

detected using

DinSAR

D. Remy et al.

Title Page

Abstract

Introduction

Conclusions

References

Tables

Figures

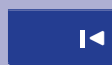

14

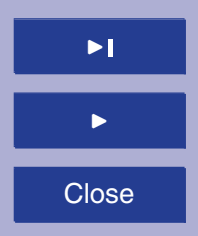

Back

Close

Full Screen / Esc

Printer-friendly Version

Interactive Discussion 
Okuyama, S., Takemoto, S., Murakami, M., Tobita, M., Fijuwara, S., Nakagawa, H., and Yarai, $\mathrm{H}$.: Detection of Crustal Deformation in Sakurajima by means of L-band SAR Interferometry based on JERS-1 SAR Images During 1992-1998, INSAR Workshop, Tokyo, Japan, 2001.

Omori, F.: The Sakurajima eruptions and earthquakes, Bull. Volcanol. Soc. Jpn, 8, 1-525, 1916.

Remy, D., Bonvalot, S., Briole, P., and Murakami, M.: Accurate measurement of tropospheric effects in volcanic area from SAR interferometry data: Application to Sakurajima volcano (Japan), Earth Planet. Sci. Lett., 213(3-4), 299-310, 2003.

Schmidt, D. A. and Burgmann, R.: Time-dependant land uplift and subsidence in the Santa Clara valley, California, from a large interferometric synthetic aperture radar data set, J. Geophys. Res., 108(B9), 2416, doi:10.1029/2202JB002267, 2003.

Sharroo, R., Visser, P. N. A. M., and Met, G. J.: Precise orbits determination and gravity field improvement for the ERS satellites, J. Geophys. Res., 103(C), 8113-8127, 1998.

Sigmundsson, F., Durand, P., and Massonnet, D.: Opening of an eruptive fissure and seaweard displacement at Piton de la Fournaise volcano measured by RADARSAT satellite radar interferometry, Geophys. Res. Lett., 26, 533-536, 1999.

Usai, S., Del Gaudio, C., Borgstrom, S., and Achili, V.: Monitoring terrain deformation at Phlegrean Fields with SAR interferometry, 2nd International Workshop on SAR interferometry (FRINGE99), Belgium, 1999.

20 Yokoyama, I.: A model for the crustal deformation around volcanoes, J. Phys. Earth, 19, 199207, 1971.
1, 151-165, 2006

Inflation of Aira

Caldera (Japan)

detected using

DinSAR

D. Remy et al.

\section{Title Page}

\section{Abstract}

Introduction

Conclusions

References

Tables

Figures

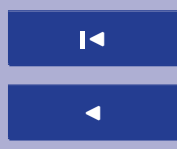

Back

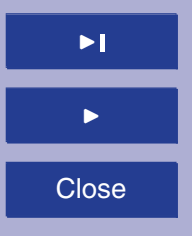

Full Screen / Esc

Printer-friendly Version

Interactive Discussion 
1, 151-165, 2006

Inflation of Aira

Caldera (Japan) detected using

DinSAR

Table 1. List of ERS-1 and ERS-2 radar images used in this study.

\begin{tabular}{cccc}
\hline Orbite & Date & $\mathrm{B} \perp(\mathrm{m})$ & Days \\
\hline 20503 & $17 / 06 / 95$ & 0 & 0 \\
21004 & $22 / 07 / 95$ & 344 & 35 \\
21505 & $26 / 08 / 95$ & 72 & 70 \\
23509 & $13 / 01 / 96$ & 191 & 210 \\
03836 & $14 / 01 / 96$ & 65 & 211 \\
25513 & $01 / 06 / 96$ & -332 & 350 \\
10850 & $18 / 05 / 97$ & 162 & 701 \\
18365 & $25 / 10 / 98$ & 203 & 1226 \\
18866 & $29 / 11 / 98$ & 115 & 1261 \\
\hline
\end{tabular}

D. Remy et al.

Title Page

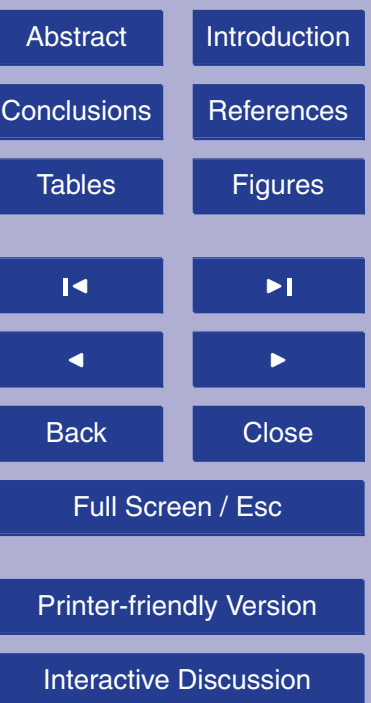


$1,151-165,2006$

Inflation of Aira

Caldera (Japan) detected using

DinSAR

D. Remy et al.

Table 2. Inversion solutions for point source models for the three selected interferograms.

\begin{tabular}{ccccccc}
\hline Master & Slave & days & $\begin{array}{c}X \\
\left({ }^{\circ}\right)\end{array}$ & $\begin{array}{c}Y \\
\left({ }^{\circ}\right)\end{array}$ & $\begin{array}{c}\mathrm{V} \\
\left(\mathrm{m}^{3}\right)\end{array}$ & $\begin{array}{c}\mathrm{Rms} \\
(\mathrm{mm})\end{array}$ \\
\hline 20503 & 10850 & 701 & 130.71 & 31.68 & $2910^{6}$ & 3 \\
21004 & 10850 & 666 & 130.71 & 31.68 & $2910^{6}$ & 4 \\
21505 & 10850 & 631 & 130.71 & 31.69 & $3010^{6}$ & 4 \\
\hline
\end{tabular}

Title Page

Abstract

Introduction

Conclusions

References

Tables

Figures

14

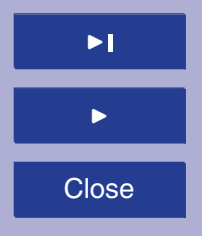

Back

Close

Full Screen / Esc

Printer-friendly Version

Interactive Discussion 


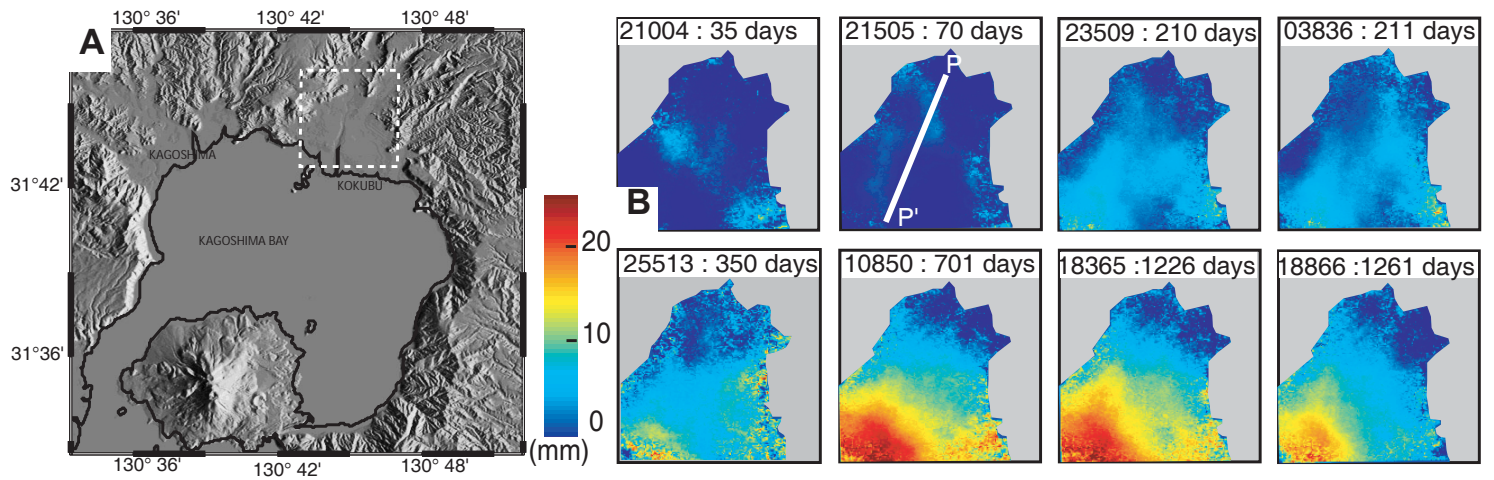

Fig. 1. (A) Location of the studied area of Aira Caldera (Japan). Inset selection corresponds to the Kokubu city area used in this study for SAR data analysis and modeling; (B) Inverted deformation field $(\mathrm{mm})$ for each of the 8 ERS images relative to the earliest image of the data set (June 1995). P and P' denote the reference profile used in the data analysis.

1, 151-165, 2006

Inflation of Aira

Caldera (Japan)

detected using

DinSAR

D. Remy et al.

\section{Title Page}

\section{Abstract}

Conclusions

Tables

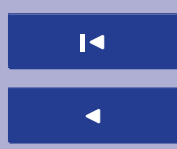

Back

Full Screen / Esc

Printer-friendly Version

Interactive Discussion 

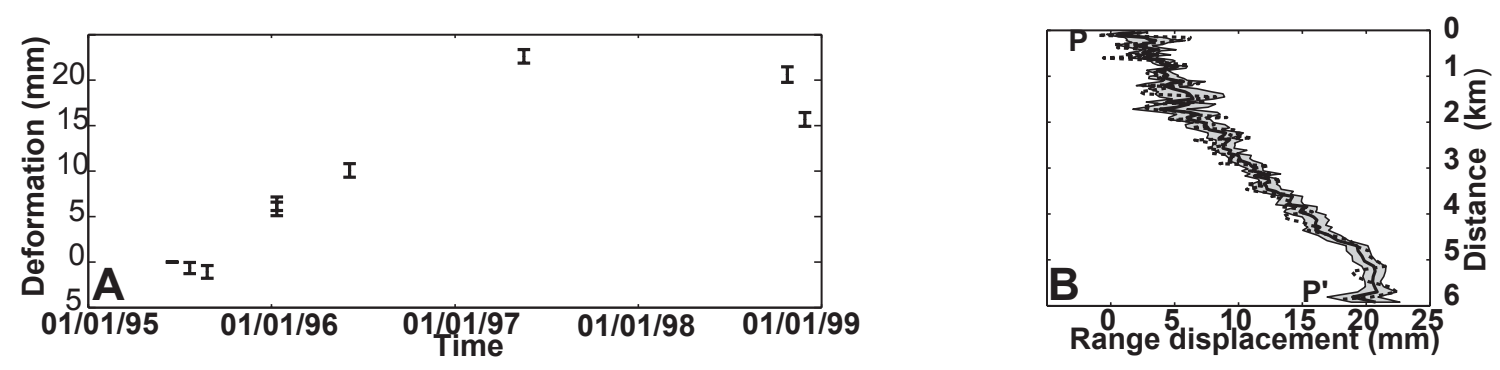

Fig. 2. (A) Maximum relative ground deformation signal evidenced from ERS data between north and south Kokubu (PP' profile) for various acquisition dates. The amplitudes and the standard deviation (vertical error bars) of the maximum uplift values are taken from a $10 \times 50$ pixels E-W cross section centred on the area of the maximum uplift around P'. The maximum amplitude of the uplift reaches $23 \mathrm{~mm}$ between June 1995 and May 1997; (B) Example of adjustment of deformation signal, along profile PP', between raw DinSAR time series (dashed line) and adjusted ones obtained from the 8 images (solid line). The shaded envelope indicates the standard deviation of the adjusted time series observed for each pixel.
Inflation of Aira

Caldera (Japan)

detected using

DinSAR

D. Remy et al.

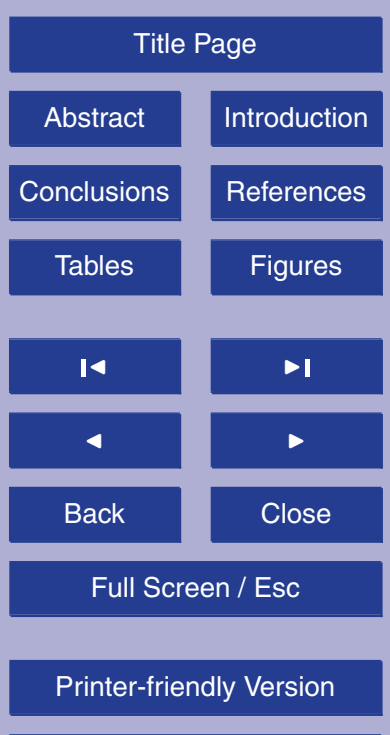

Interactive Discussion 

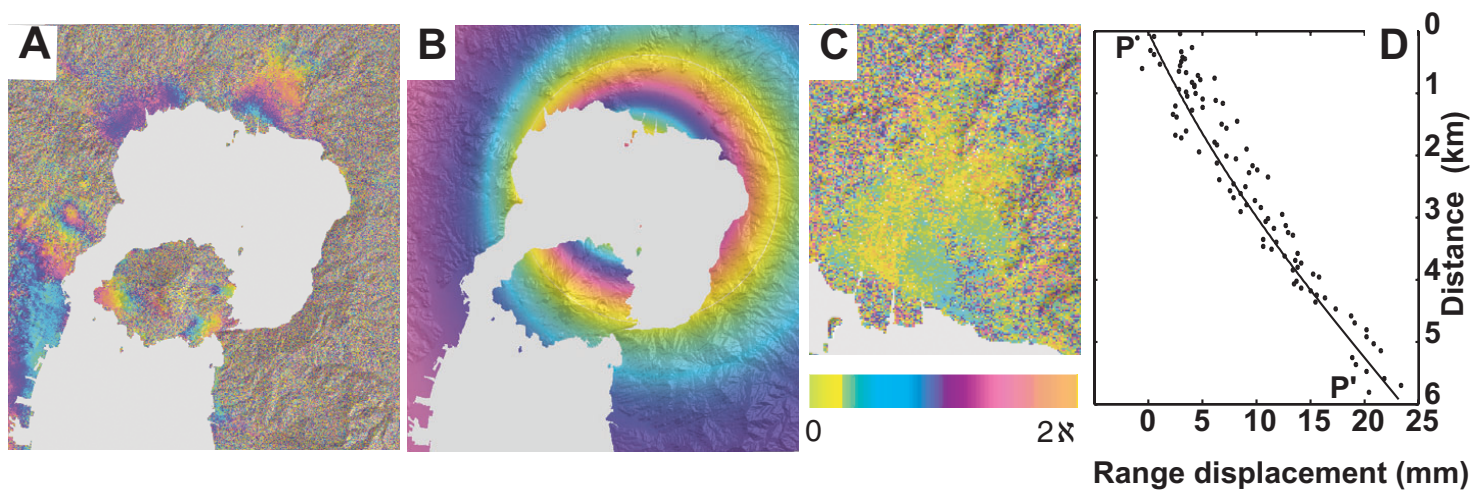

Fig. 3. (A) Filtered interferogram obtained from the phase difference of SAR image orbits (20503, 10850) spanning more than one year (17 June 1995 and 18 May 1997). The phase signal is clearly visible on Kokubu city and corresponds to about $23 \mathrm{~mm}$ of total displacement along the sensor line of sight as confirmed by the time series analysis; (B) Best fit model found using a Mogi modeling approach expressed in wrapped phase value; (C) Residual wrapped phase values between observed and modeled data over coherent area of Kokubu city; (D) Corresponding observed (dots) and modeled (solid line) relative range displacements along the profile PP'.
1, 151-165, 2006

\section{Inflation of Aira Caldera (Japan) detected using DinSAR}

D. Remy et al.

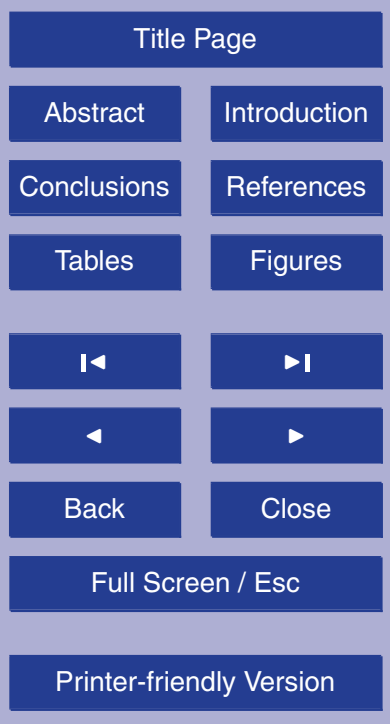

Interactive Discussion 